\title{
Effect of Operating Parameters on Hydrothermal Liquefaction of Sugarcane Bagasse
}

\author{
Gideon van Rensburg, Rouxné Kruger, and Sanette Marx
}

\begin{abstract}
Hydrothermal liquefaction (HTL) is a thermochemical process that produces various products from lignocellulosic feedstocks. In this study sugar cane bagasse was used as feedstock for HTL. Experiments were carried out in a batch reactor, at varying operating conditions to investigate the effect on the product yields and product composition. The reactor temperature, heating rate, and retention time were varied, while the volume loading of the reactor and feedstock to water ratio were kept constant. Nitrogen was used to pressurize the reactor for all experiments. It was found that none of the operating conditions have a significant effect on the parameters studied.
\end{abstract}

Keywords - Aqueous phase, hydrothermal liquefaction (HTL), lignocellulosic biomass, sugarcane bagasse.

\section{INTRODUCTION}

As the global energy use is projected to increase by $38 \%$ from 2010 to 2040 [1], alternatives to the dominant use of fossil fuels need to be found. For this reason the use of renewable sources are gaining importance.

Various biomass feedstocks have been investigated as a source of renewable energy. These include micro - and macro algal biomass, agricultural -, forestry -, and municipal wastes, both raw and treated sewage sludge, and manures. [2]-[5]

Several thermochemical conversion technologies are available to transform the above mentioned biomass into fuels. The main technologies are [3], [4]:

- hydrothermal gasification

- $\quad$ hydrothermal liquefaction (HTL)

- pyrolysis

- direct combustion

- $\quad$ supercritical fluid extraction

- hydrothermal carbonization

Of these processes, pyrolysis and HTL are comparable, as both technologies transform biomass into liquid energy carriers [6]. The major difference between these processes being the water content of the feedstock: Pyrolysis requires a dry feedstock, while wet feedstocks can be processed in HTL [2]-[4], [7]. For this reason, HTL is also defined as the

Mannuscript received October 20, 2018. This work was supported by the National Research Foundation (grant UID 91635)

$G$ van Rensburg is with the DST/NRF Research Chair in Biofuels, Centre of Excellence in Carbon Based Fuels, Faculty of Engineering, North-West University, Potchefstroom, South Africa

R. Kruger was with the DST/NRF Research Chair in Biofuels, Centre of Excellence in Carbon Based Fuels, Faculty of Engineering, North-West University, Potchefstroom, South Africa

S. Marx with the DST/NRF Research Chair in Biofuels, Centre of Excellence in Carbon Based Fuels, Faculty of Engineering, North-West University, Potchefstroom, South Africa. thermochemical conversion of biomass into liquid fuels in a hot, pressurized water environment [2].

Although the production of liquid fuels is the main focus of HTL, several other products are formed during the process [3], [5], [6], [8]. These products are:

- An organic, bio-oil phase, also called biocrude. This phase consists of both polar and non-polar organic compounds that can either be used as fuels or as precursors to fuels.

- A gas phase. This phase consists mainly of $\mathrm{H}_{2}, \mathrm{CO}$, $\mathrm{CO}_{2}$, short chained alkanes, and other volatile organic compounds.

- An aqueous phase. This phase is produced from the water contained in the feedstock, the water used as a solvent, and water formed as product during HTL reactions. Various organic compounds formed during HTL is also dissolved in this phase.

- A solid, biochar phase. This phase consists of the solid residue that is formed during HTL.

As the production of fuels is the main objective of HTL processes, past studies mainly focused on optimizing the conditions for the production of bio-oil and -char without studying the effect on the composition of the phases produced. It is therefore possible that valuable compounds in these products are lost without proper utilization resulting in a negative impact on the techno-economics of HTL.

\section{BACKGROUND}

Biomass is defined as being organic compounds derived from microorganisms, plants, and animals, as well as the waste and residues derived from their processing such as agricultural waste, forestry residues, and municipal waste [5].

Biomass is also further classified according to its origin as being either first -, second -, or third generation feedstocks [9]. This classification is summarized in Table I.

TABLE I: THE CLASSIFICATION OF BIOMASS FEEDSTOCKS

\begin{tabular}{|c|c|}
\hline Generation & Feedstock \\
\hline First Generation & Starch and sugars (food crops) \\
\hline Second Generation & $\begin{array}{c}\text { Non-food crops (oil crops), } \\
\text { agricultural and forestry residues }\end{array}$ \\
\hline Third Generation & Algae \\
\hline
\end{tabular}

\section{A. Lignocellulosic biomass}

Lignocellulosic biomass is a second generation feedstock and comprises, as the name suggests, mainly of cellulose, hemicellulose, lignin, and extractives [9]. (This is opposed to algal biomass that is composed of carbohydrates, lipids and proteins [10]). 


\section{1) Cellulose}

Cellulose is a linear polymer of $\beta$-D-glucopyranose units linked with $\beta$-1,4-glycosidic bonds, and makes up $40-50 \%$ of plant based biomass [11].

Cellulose also has a tendency to form intra- and intermolecular hydrogen bonds. This leads to bundles of cellulose molecules to collect into micro fibrils, which in turn form either crystalline (i.e. highly ordered) or amorphous (less ordered) regions. These micro fibrils again collect to form fibrils and ultimately cellulose fibers [11].

The tight structure created by the hydrogen bonds results in cellulose being highly insoluble in most solvents, but it becomes partially soluble in water at $302{ }^{\circ} \mathrm{C}$ and is completely soluble at $330{ }^{\circ} \mathrm{C}$ under subcritical conditions [12].

\section{2) Hemicellulose}

Hemicellulose is a group of heteroplysaccharides that make up $20-30 \%$ of plant based biomass, with wood usually having a higher content than agricultural biomass. The most abundant monosaccharide monomers of hemicellulose are D-glucose, D-mannose, D-galactose, D-xylose, L-arabinose, and L-rhamnose [11].

Because hemicellulose has a less ordered structure than cellulose, it also degrades more easily when subjected to heat treatment [4].

\section{3) Lignin}

Lignin is, as with cellulose and hemicellulose, a biopolymer, but differs by having an amorphous structure. Lignin is composed of p-hydroxyphenylpropanoid units which are linked by C-C or C-O-C (ether) bonds. The three major monomers of lignin are p-coumaryl alcohol, coniferyl alcohol, and sinapyl alcohol [11].

Lignin functions as a binder for cellulose and hemicellulose fibers within plant tissues and therefore the lignin content for biomass varies from $13-33 \%$, with wood having a higher lignin content than biomass obtained from herbaceous plants [13].

\section{B. Hydrothermal liquefaction as thermochemical process}

Several technologies exist to process biomass into fuels. These technologies can be classified as either thermochemical or biochemical [13]. Thermochemical processes are again subdivided into combustion, pyrolysis and hydrothermal processes [4]. Hydrothermal liquefaction (HTL) is one of the hydrothermal conversion technologies available to process biomass into fuels. The other processes being hydrothermal gasification and hydrothermal carbonization [9], [13].

HTL is performed in pressures ranging from $4-22 \mathrm{MPa}$ (some studies use self-generated pressure) and temperatures of $250-374{ }^{\circ} \mathrm{C}$ [3]. At these conditions (below the critical point of water), water remains in a liquid state and acts as both solvent and catalyst for the reactions that take place [4]. The increased pressure and temperature also causes hydrocarbons to become more soluble in water [3]. For this reason, subcritical water is an efficient medium for fast, homogeneous reactions for hydrocarbons during HTL [6].

\section{Reactions of lignocellulosic biomass during HTL \\ 1) Reactions of cellulose and hemicellulose}

As cellulose and hemicellulose are biopolymers with saccharides as monomers, both compounds undergo similar reactions during HTL.

Water at high pressure and temperature breaks down the inter- and intramolecular hydrogen bonded structure of cellulose and subsequently causes the formation of glucose and other oligomers of cellulose. These oligomers can be further hydrolyzed and converted into glucose [4].

The glucose and others monosaccharides from cellulose and hemicellulose exist as tautomers [14], i.e. the structures of the sugars vary only in the position of different bonds between the atoms within the structures. The products formed by the degradation of these sugars include carboxylic acids, ketones, aldehydes, furans (furfural derivatives), and phenolic compounds and these compounds are all are highly soluble in water [4], [6], [15]. It was also reported that the short organic acids that form may degrade further into gaseous products [14], but there reactions were reported to only occur at temperatures exceeding $374{ }^{\circ} \mathrm{C}[6]$.

Of the carboxylic acids produced during HTL, glycolic acid and lactic acid may undergo further condensation reactions to produce oxygenated aromatics such as phenol and catechol [14].

\section{2) Reactions of lignin}

Lignin is the main source of phenolic products during HTL and tends to produce significant amounts of (solid) biochar during HTL [16]. It is proposed that the char that forms from lignin is produced from uncontrolled condensation and degradation reactions of the phenolic compounds present [6].

During HTL lignin undergoes hydrolysis to form various methoxylated benzenes, aromatic oligomers and short chained (C2 - C6) oxygenated hydrocarbons [10]. The methoxylated benzenes can undergo further hydrolysis to produce hydroxylated benzenes. Alkylation of these products also occur, producing alkylated benzenes and aromatic oligomers [17].

It is important to note that in some studies of the HTL of feedstocks that have a high lignin content (Kraft - and Organosolv lignin, as well as walnut shells), the products were biochar and aqueous phase with no biocrude phase forming [6].

\section{MATERIALS AND METHODS}

\section{A. Feedstock}

Sugarcane bagasse supplied by the Sugar Milling Research Institute was used as a feedstock for this study.

A fiber analysis was conducted according to the Van Soest method [18] to determine the cellulose, hemicellulose and lignin content of the bagasse. A sample was also sent to Bureau Veritas Testing and Inspections South Africa for an ultimate analysis (C, H, and N). A proximate analysis [19] was also done to determine the moisture, volatile, ash, and fixed carbon content of the bagasse. The results for the compositional analyses of the feedstock is summarized in Tables I, II, and III. 
SEM micrographs of the feedstock, showing the variations in plant tissues, are given in Fig. 1.

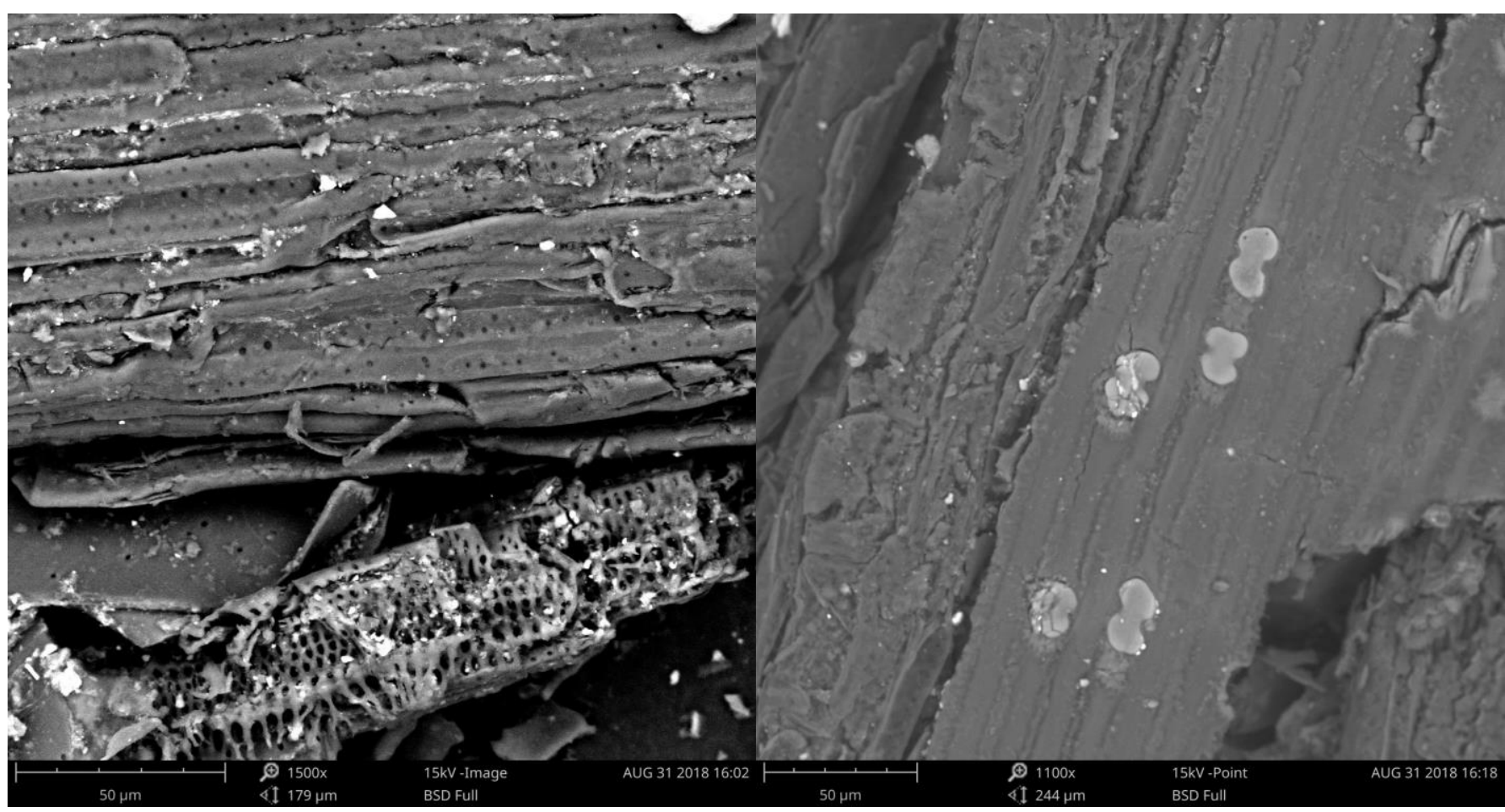

FIG. 1: SUGARCANE BAGASSE MICROGRAPHS

Table II: Feedstock fiber analysis

\begin{tabular}{|l|l|}
\hline Cellulose & $29.9 \mathrm{wt} \%$ \\
\hline Hemicellulose & $35.2 \mathrm{wt} \%$ \\
\hline Raw lignin & $7.69 \mathrm{wt} \%$ \\
\hline
\end{tabular}

TABLE III: FEEDSTOCK PROXIMATE ANALYSIS

\begin{tabular}{|l|l|}
\hline Total moisture & $7.5 \pm 0.3 \mathrm{wt} \%$ \\
\hline Volatile matter & $74.4 \pm 0.1 \mathrm{wt} \%$ \\
\hline Fixed carbon & $5.3 \pm 0.6 \mathrm{wt} \%$ \\
\hline Ash & $13.2 \pm 0.8 \mathrm{wt} \%$ \\
\hline
\end{tabular}

TABLE IV: FEEDSTOCK ULTIMATE ANALYSIS

\begin{tabular}{|l|l|}
\hline Carbon & $37.8 \mathrm{wt} \%$ \\
\hline Hydrogen & $5.36 \mathrm{wt} \%$ \\
\hline Nitrogen & $0.45 \mathrm{wt} \%$ \\
\hline
\end{tabular}

\section{B. Experimental equipment}

HTL runs were carried out in a reactor constructed from 316 stainless steel, fitted with an external heating mantle. The volume of the reactor was $0.954 \mathrm{~L}$. The reactor was also fitted with a pressure gauge to monitor the internal pressure during reactions. Thermocouples were used to measure the internal temperature and also to monitor the temperature of the heating mantle in order to regulate the heating rate of the reactor. A 316 stainless steel insert was used to facilitate the loading and removal of the reactor content.

Design-Expert ${ }^{\circledR}$ Version 7.1.5 was used to construct a general factorial design of the experiments done. The factors that were varied was heating rate $(\Delta T)$, reaction temperature $(T)$, and residence time $(\tau)$. The values for these factors are given in Table $\mathrm{V}$.
TABLE V: EXPERIMENTAL VARIABLES

\begin{tabular}{|c|c|}
\hline Variable & Values \\
\hline$\Delta T\left({ }^{\circ} \mathrm{C} / \mathrm{min}\right)$ & $2 ; 4$ \\
\hline$T\left({ }^{\circ} \mathrm{C}\right)$ & $280 ; 300 ; 320$ \\
\hline$\tau(\min )$ & $15 ; 30 ; 45$ \\
\hline
\end{tabular}

The factors that were kept constant was reactor volume loading, feedstock to water (1:6 by mass), and all experiments were carried out using Nitrogen to pressurize the reactor.

\section{Product extraction}

After HTL was completed, the reaction products were extracted and recovered. The contents, consisting of biochar, aqueous phase and oils, were poured into a Buchner funnel fitted with filter paper and connected to a vacuum pump. The aqueous phase was filtered from the reaction products. Hexane was then used to wash the biochar and the non-polar oils. The liquids separated from the solids during this step was then transferred to a separating funnel where the water and hexane phases were separated. The biochar was then further washed with acetone to remove the polar oils. The washed biochar was transferred to an oven and dried at $60{ }^{\circ} \mathrm{C}$ for 3 hours. After drying, the biochar was stored in screw top containers under a Nitrogen atmosphere until analysis.

The acetone and hexane fractions obtained from washing the reaction products were both evaporated under vacuum to obtain the polar (acetone soluble) and non-polar (hexane soluble) oils using a BUCHI Rotavapor R II. Once the solvents were evaporated, the oils obtained and the aqueous 
phase was refrigerated until analysis.

The product yields were calculated as follows:

Biochar Yield $=\frac{\text { Mass of biochar }}{\text { Mass of feedstock }}$

Oil Yield $=\frac{\text { Mass of polar oil }+ \text { Mass of non-polar oil }}{\text { Mass of feedstock }}$

Gas Yield $=\frac{\text { Mass of gas }}{\text { Mass of feedstock + Mass of solvent }}$

Aqeous phase Yield $=\frac{\text { Mass of aqueous phase }}{\text { Mass of feedstock+ Mass of solvent }}$

\section{Product characterization}

a) Higher heating value (HHV)

The HHV of the feedstock and the biochar was determined using an IKA®C500 bomb calorimeter, calibrated using benzoic acid as standard.

b) Scanning electron microscopy (SEM) A Phenom ProX desktop SEM was used to characterize the feedstock and biochar produced.

c) Proximate analysis

The total moisture, volatile matter and ash content of the feedstock and biochar were obtained by the methods prescribed in SANS 17246:2011. Ashing was done at $900{ }^{\circ} \mathrm{C}$.

d) Total organic carbon (TOC), Total Nitrogen (TN), and Phenolic index

The TOC, TN and Phenolic index for the aqueous phase was measured using Macherey-Nagel NANOCOLOR® TOC 600, Macherey-Nagel NANOCOLOR® TN 220, and Merck Spectroquant Phenol tests respectively.

\section{RESULTS AND DISCUSSION}

\section{A. Product yields}

Fig. $2-4$ show the different products obtained at the various operating conditions. The results show that there were no significant effect of any parameter on the product yields.

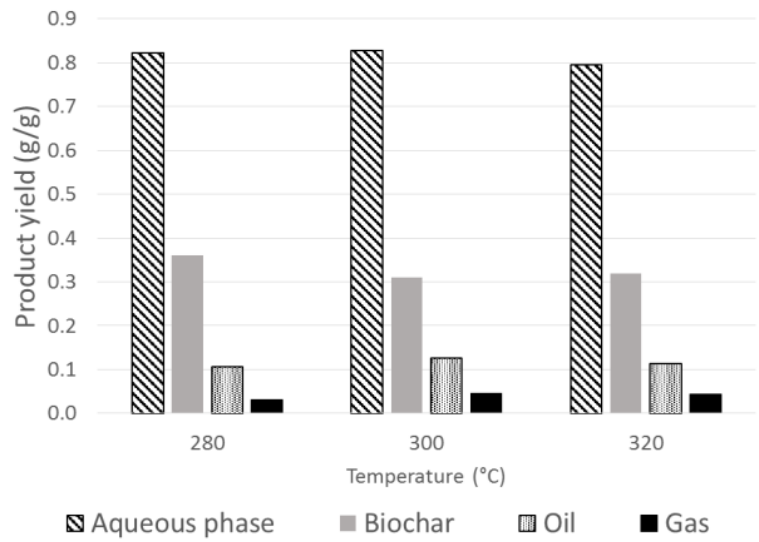

FIG. 2: EFFECT OF TEMPERATURE ON PRODUCT YIELDS

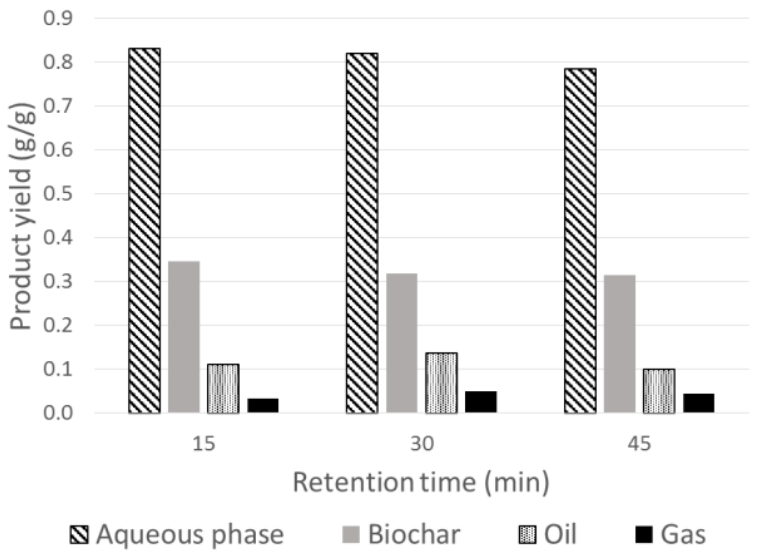

FIG. 3: EFFECT OF RETENTION TIME ON PRODUCT YIELDS

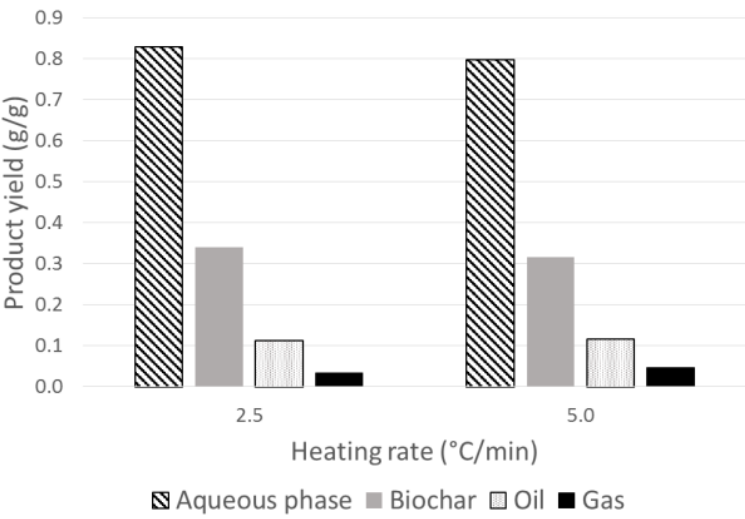

FIG. 4: EFFECT OF HEATING RATE ON PRODUCT YIELDS

\section{B. Effect on oil and char properties}

Fig. $5-7$ show the effect of the different operating parameters on the composition of the chars produced with regards to moisture content, volatile matter, ash content, and fixed Carbon content. Again, these results show that there were no significant effect on the composition of the chars.

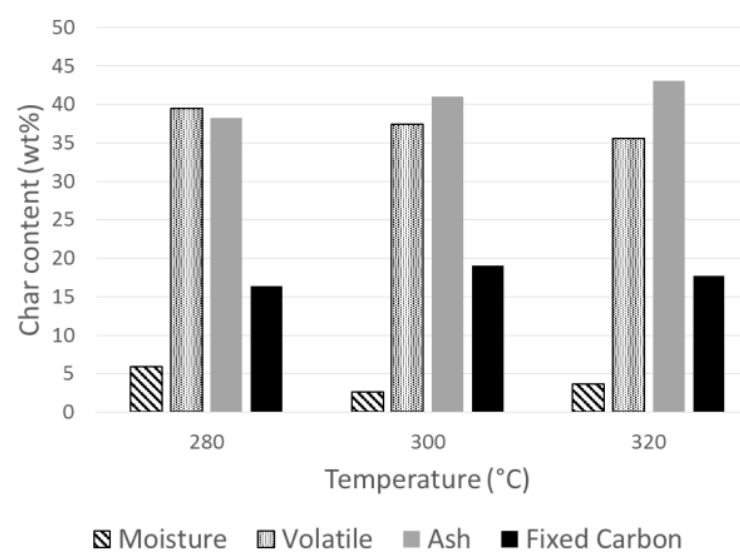

FIG. 5: EFFECT OF TEMPERATURE ON CHAR COMPOSITION 


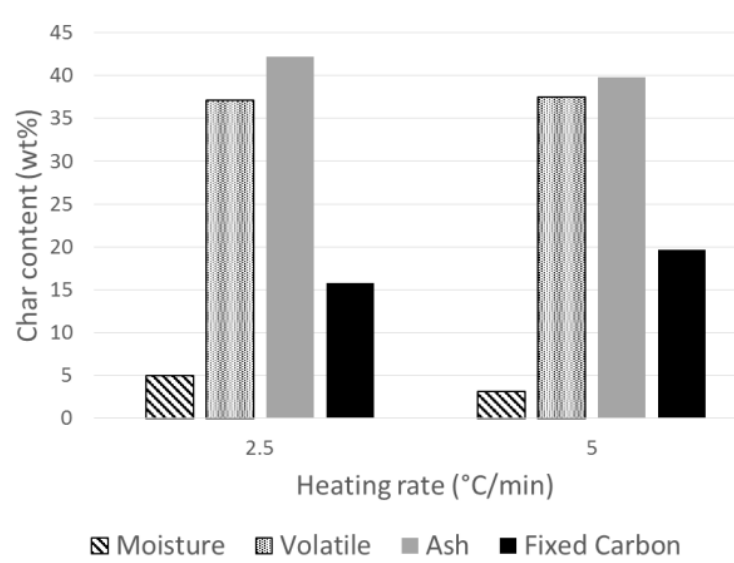

FIG. 6: EFFECT OF HEATING RATE ON CHAR COMPOSITION

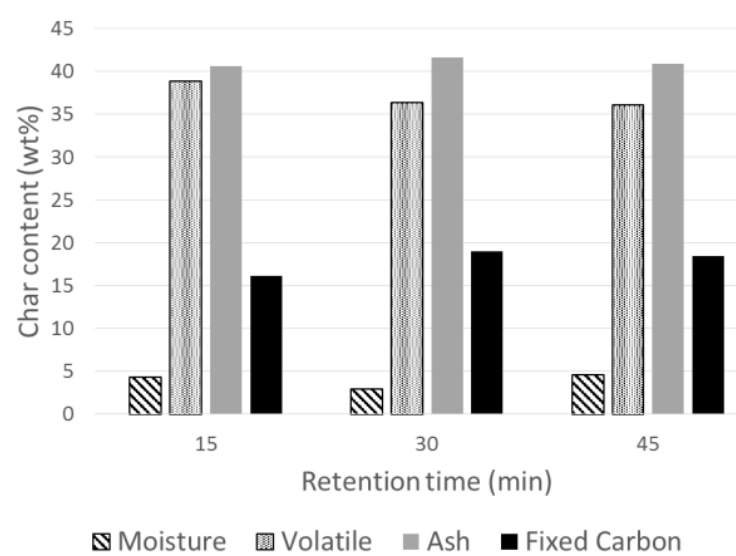

FIG. 7: EFFECT OF RETENTION TIME ON CHAR COMPOSITION

The effect of the operating conditions on the higher heating value (HHV) of the oil produced is shown in Table VI. As with the char composition, varying the operating conditions have no effect on the HHV of the oils.

\begin{tabular}{|c|c|}
\hline Temperature $\left({ }^{\circ} \mathrm{C}\right)$ & HHV (MJ/kg) \\
\hline 280 & 23.822 \\
\hline 300 & 24.534 \\
\hline 320 & 25.115 \\
\hline \multicolumn{2}{|l|}{ Heating rate $\left({ }^{\circ} \mathrm{C} / \mathrm{min}\right)$} \\
\hline 2.5 & 24.912 \\
\hline 5.0 & 24.192 \\
\hline \multicolumn{2}{|l|}{ Retention time (min) } \\
\hline 15 & 24.373 \\
\hline 30 & 24.579 \\
\hline 45 & 24.766 \\
\hline
\end{tabular}

\section{Effect on aqueous phase}

To measure the effect of the varied parameters on the aqueous phase, the total organic Carbon (TOC) and the total phenolic content was determined. These results are shown in Fig. 8 - 10. An ANOVA analysis was done on the results to determine which parameters have a significant effect on the composition of the aqueous phase. The p-values obtained varied from 0.1993 to 0.7678 for the response factors for the TOC of the aqueous phase, and from 0.4220 to 0.9741 for the response factors for the total phenol content of the aqueous phase.

The results for the ANOVA analysis indicates that none of the parameters, or any combination of parameters have a significant influence on the aqueous phase composition as all of the p-values calculated are larger than 0.05. (Response factors of variables or combinations of variables with a p-value less than 0.05 are considered to be significant)

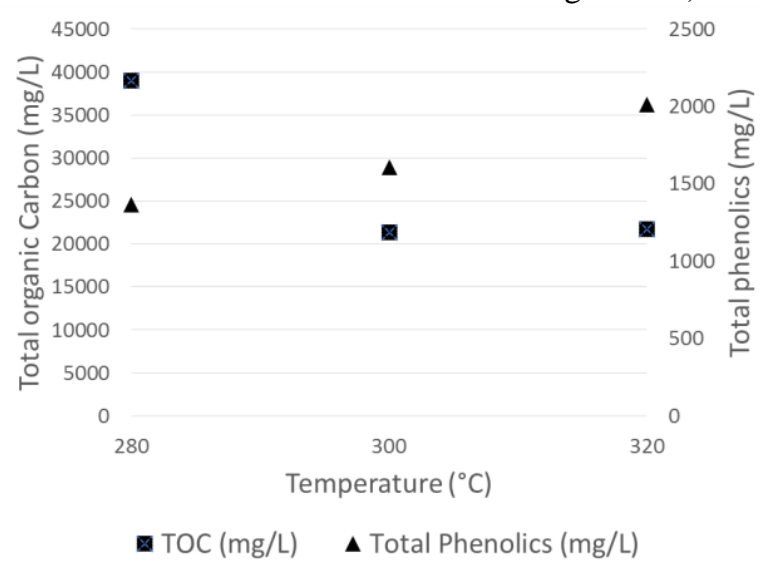

FIG. 8: EFFECT OF TEMPERATURE ON AQUEOUS PHASE COMPOSITION

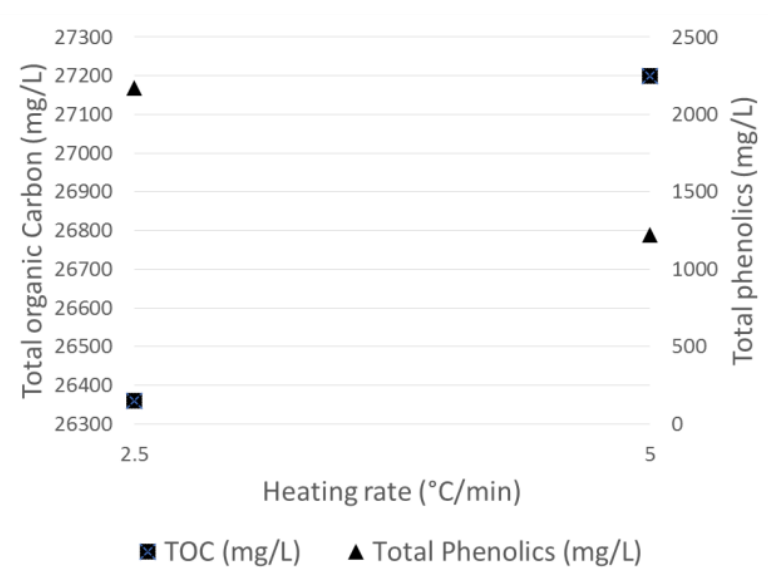

FIG. 9: EFFECT OF HEATING RATE ON AQUEOUS PHASE COMPOSITION

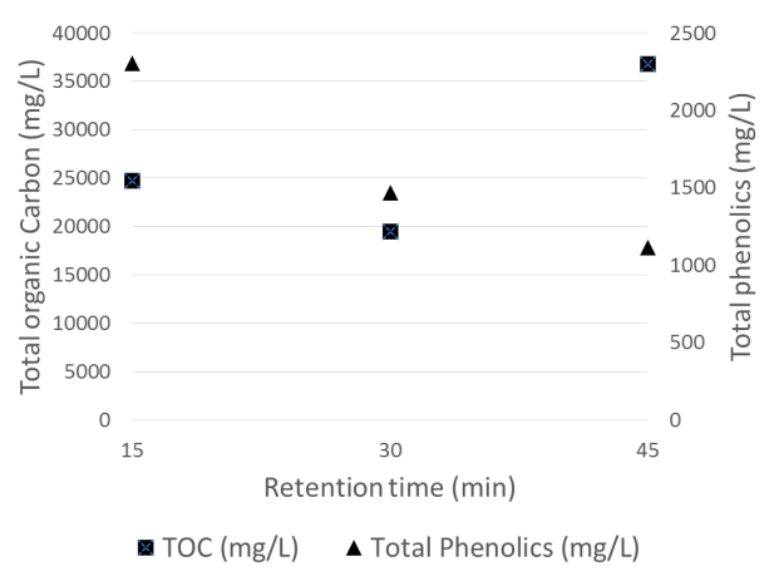

FIG. 10: EFFECT OF RETENTION TIME ON AQUEOUS PHASE COMPOSITION

\section{CONCLUSIONS AND RECOMMENDATIONS}

As there are limited results reported in literature with regards to the different organic compounds found in the aqueous phase, further studies should be carried out to identify and quantify the phenolic compounds present. There is a possibility that these compounds can be of economic value. 
As HTL is an energy intensive process that utilizes relative high heat and pressures. The results from this study has shown that energy can be conserved by reducing the operating temperature and retention times for batch HTL runs without having an effect on the product yields.

\section{REFERENCES}

[1] A. Sieminski, "International Energy Outlook," U.S. Energy Inf. Adm. 2014.

[2] D. C. Elliott, P. Biller, A. B. Ross, A. J. Schmidt, and S. B. Jones, "Hydrothermal liquefaction of biomass: Developments from batch to continuous process," Bioresour. Technol., vol. 178, pp. 147-156, 2015. https://doi.org/10.1016/j.biortech.2014.09.132

[3] A. Dimitriadis and S. Bezergianni, "Hydrothermal liquefaction of various biomass and waste feedstocks for biocrude production: A state of the art review," Renew. Sustain. Energy Rev., vol. 68, no. October 2016, pp. 113-125, 2017.

[4] K. Tekin, S. Karagöz, and S. Bektaş, "A review of hydrothermal biomass processing," Renew. Sustain. Energy Rev., vol. 40, pp. 673687, 2014.

https://doi.org/10.1016/j.rser.2014.07.216

[5] L. Cao, C. Zhang, H. Chen, D. C. W. Tsang, G. Luo, S. Zhang, and J. Chen, "Hydrothermal liquefaction of agricultural and forestry wastes: state-of-the-art review and future prospects," Bioresour. Technol., vol. 245, no. September, pp. 1184-1193, 2017. https://doi.org/10.1016/j.biortech.2017.08.196

[6] S. S. Toor, L. Rosendahl, and A. Rudolf, "Hydrothermal liquefaction of biomass: A review of subcritical water technologies," Energy, vol. 36 , no. 5, pp. 2328-2342, 2011. https://doi.org/10.1016/j.energy.2011.03.013

[7] Z. Zhu, L. Rosendahl, S. S. Toor, D. Yu, and G. Chen, "Hydrothermal liquefaction of barley straw to bio-crude oil: Effects of reaction temperature and aqueous phase recirculation," Appl. Energy, vol. 137, pp. 183-192, 2015. https://doi.org/10.1016/j.apenergy.2014.10.005

[8] R. B. Madsen, P. Biller, M. M. Jensen, J. Becker, B. B. Iversen, and M. Glasius, "Predicting the Chemical Composition of Aqueous Phase from Hydrothermal Liquefaction of Model Compounds and Biomasses," Energy and Fuels, vol. 30, no. 12, pp. 10470-10483, 2016.

https://doi.org/10.1021/acs.energyfuels.6b02007

[9] M. Fatih Demirbas, "Biorefineries for biofuel upgrading: A critical review," Appl. Energy, vol. 86, no. SUPPL. 1, pp. S151-S161, 2009.

[10] D. López Barreiro, S. Riede, U. Hornung, A. Kruse, and W. Prins, "Hydrothermal liquefaction of microalgae: Effect on the product yields of the addition of an organic solvent to separate the aqueous phase and the biocrude oil," Algal Res., vol. 12, pp. 206-212, 2015. https://doi.org/10.1016/j.algal.2015.08.025

[11] E. Sjöström and U. Westermark, Analytical Methods in Wood Chemistry, Pulping, and Papermaking. Berlin, Heidelberg: Springer Berlin Heidelberg, 1999. https://doi.org/10.1007/978-3-662-03898-7

[12] R. Posmanik, R. A. Labatut, A. H. Kim, J. G. Usack, J. W. Tester, and L. T. Angenent, "Coupling hydrothermal liquefaction and anaerobic digestion for energy valorization from model biomass feedstocks," Bioresour. Technol., vol. 233, pp. 134-143, 2017. https://doi.org/10.1016/j.biortech.2017.02.095

[13] Z. Anwar, M. Gulfraz, and M. Irshad, "Agro-industrial lignocellulosic biomass a key to unlock the future bio-energy: A brief review," $J$. Radiat. Res. Appl. Sci., vol. 7, no. 2, pp. 163-173, 2014. https://doi.org/10.1016/j.jrras.2014.02.003

[14] R. B. Madsen, R. Z. K. Bernberg, P. Biller, J. Becker, B. B. Iversen, and M. Glasius, "Hydrothermal co-liquefaction of biomasses quantitative analysis of bio-crude and aqueous phase composition," Sustain. Energy Fuels, vol. 1, no. 4, pp. 789-805, 2017. https://doi.org/10.1039/C7SE00104E

[15] A. R. K. Gollakota, N. Kishore, and S. Gu, "A review on hydrothermal liquefaction of biomass," Renew. Sustain. Energy Rev., vol. 81, no. April 2017, pp. 1378-1392, 2018.

[16] K. R. Arturi, K. R. Toft, R. P. Nielsen, L. A. Rosendahl, and E. G. Søgaard, "Characterization of liquid products from hydrothermal liquefaction (HTL) of biomass via solid-phase microextraction (SPME)," Biomass and Bioenergy, vol. 88, pp. 116-125, 2016. https://doi.org/10.1016/j.biombioe.2016.03.010

[17] J. Barbier, N. Charon, N. Dupassieux, A. Loppinet-Serani, L. Mahé, J. Ponthus, M. Courtiade, A. Ducrozet, A. A. Quoineaud, and F. Cansell, "Hydrothermal conversion of lignin compounds. A detailed study of fragmentation and condensation reaction pathways," Biomass and
Bioenergy, vol. 46, pp. 479-491, 2012.

https://doi.org/10.1016/j.biombioe.2012.07.011

[18] P. J. Van Soest, "Use of detergents in the analysis of fibrous feeds . II . A rapid method for the determination of fiber and lignin," J. Assoc. Official Agric. Chem, vol. 46, no. 5, pp. 829-835, 1963.

[19] Standards South Africa, "SANS 17246 SOUTH AFRICAN NATIONAL STANDARD Coal: Proxiamte analysis." 2006. 